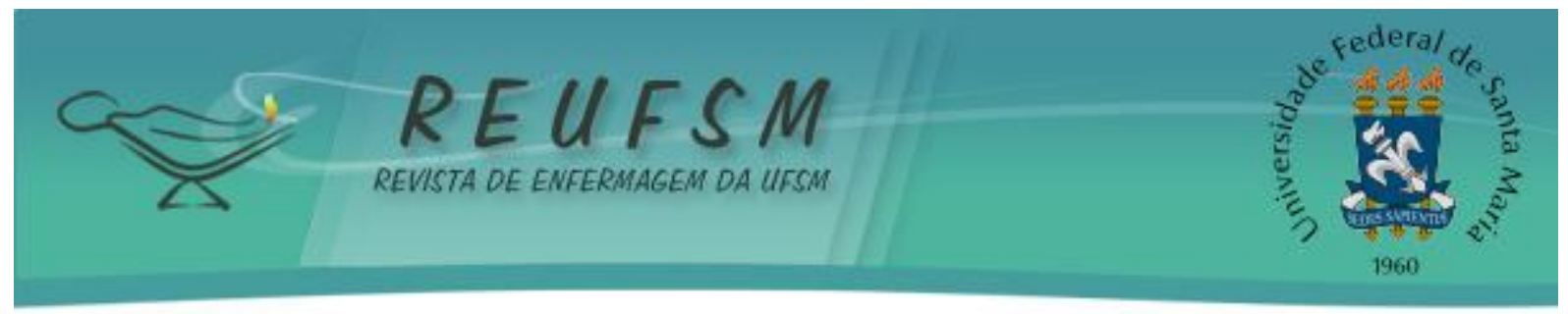

REFLEXÃO

\title{
SERVIÇOS DE TERAPIA ANTINEOPLÁSICA: SEGURANÇA DOS TRABALHADORES E RISCO QUÍMICO
}

\section{ANTINEOPLASTIC THERAPY SERVICES: WORKER SAFETY AND CHEMICAL RISK SERVICIOS DE TERAPIA ANTINEOPLÁSICA: SEGURIDAD DE LOS TRABAJADORES Y RIESGO QUÍMICO}

\author{
Maria Elaine de Oliveira Bolzan ${ }^{1}$ \\ Sandra Helena Comassetto Barros ${ }^{2}$ \\ Lenir Gebert ${ }^{3}$ \\ Laura de Azevedo Guido ${ }^{4}$
}

RESUMO: Estudo de atualização com o propósito de fazer um levantamento das ações necessárias para uma prática segura nos Serviços de Terapia Antineoplásica (STA), na perspectiva de proteção da saúde do trabalhador em relação ao risco ocupacional químico presente no ambiente de trabalho, ao manusear Quimioterapia Antineoplásica (QA). As práticas de segurança foram categorizadas em relativa aos profissionais; manipulação da QA; individual e coletiva; uso de materiais; transporte da QA; administração de QA; descarte de resíduos tóxicos; derramamento ambiental e contaminação pessoal e manuseio de pacientes, com base nos referenciais do Instituto Nacional do Câncer (INCA), de BONASSA e SANTANA e da Resolução da Diretoria Colegiada (RDC) 220. A sustentação teórica acerca da temática fornece subsídios às ações e práticas seguras ao apontar condições ideais e legais de trabalho e instrumentalizar os trabalhadores dos STA para o exercício laboral consciente e livre de riscos.

Descritores: Enfermagem; Serviço hospitalar de oncologia; Risco ocupacional; Quimioterapia; Trabalhador; Saúde.

ABSTRACT: Updated study with the purpose of making a survey of the necessary actions for a safe practice in Antineoplastic Therapy Services (ATS), in the perspective of protecting worker's health in relation to chemical occupational risk present in the work environment, while maneuvering Antineoplastic Chemotherapy (AQ). Safety practices were categorized in relative to professionals; handling of $A Q$; individual and collective; use of materials; transport of $A Q$; application of $A Q$; discard of toxic waste; environmental dumping and personal contamination and patient handling, based on benchmarks of National Institute of Cancer (NICA), and of BONASSA and SANTANA, and of Collegiate Directory Resolution (CDR) 220. The theoretical framework on the subject

\footnotetext{
${ }^{1}$ Enfermeira. Mestranda do Programa de Pós-Graduação em Enfermagem da Universidade Federal de Santa Maria. Enfermeira do Hospital Universitário de Santa Maria da Universidade Federal de Santa Maria/RS. E-mail: mariaelaine.bolzan@bol.com.br

${ }^{2}$ Enfermeira. Especialista em Administração dos Serviços de Enfermagem. Enfermeira do Hospital Universitário de Santa Maria da Universidade Federal de Santa Maria/RS. sandrahusm@yahoo.com.br

${ }^{3}$ Enfermeira. Especialista em Saúde do Adulto. Enfermeira do Hospital Universitário de Santa Maria da Universidade Federal de Santa Maria/RS. E-mail: lenirgebert@gmail.com

${ }^{4}$ Enfermeira. Doutora em Enfermagem pela Escola de Enfermagem da Universidade de São Paulo. Professora Adjunta do Departamento de Enfermagem da Universidade Federal de Santa Maria/RS. E-mail: lguido@terra.com.br
} 


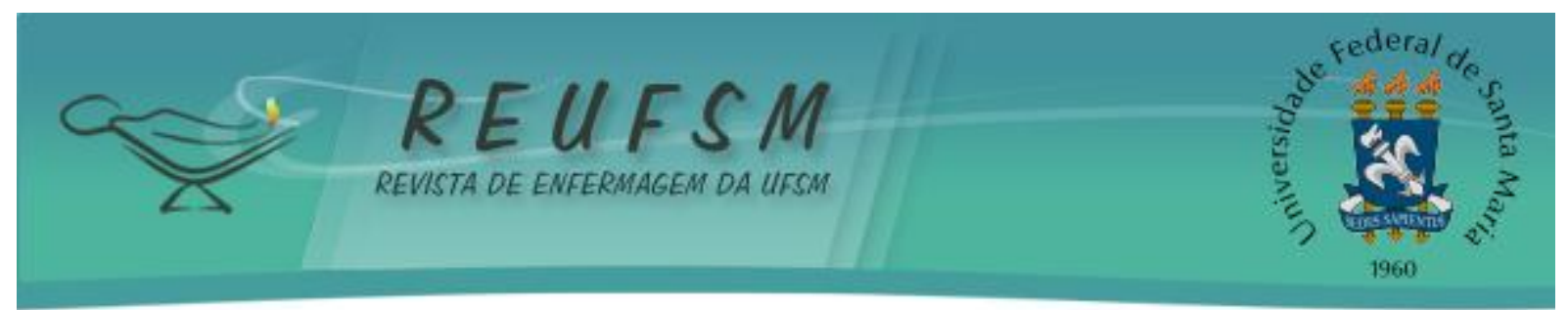

provides subsidies to safety actions and practices, pointing to ideal and legal work conditions and instrumenting the ATS workers for the conscious and risk-free labor exercise.

Descriptors: Nursing; Oncology hospital service; Occupational risk; Chemotherapy; Worker; Health.

RESUMEN: Este trabajo propone un estudio de actualización con la finalidad de hacer una encuesta sobre acciones necesarias para una práctica segura en los Servicios de Terapia Antineoplásica (STA), ambicionando una perspectiva de protección de la salud del trabajador en relación al riesgo ocupacional químico, que se encuentra en el ambiente de trabajo, cuando este manosea Quimioterapia Antineoplásica (QA). Las prácticas de seguridad fueron distribuidas en categorías según quienes las utilizan; manipulación de $Q A$; individual y colectiva; uso de materiales; transporte de $Q A$; administración de $Q A$; desechar residuos tóxicos; derramamiento ambiental, contaminación personal, manoseo de pacientes, según los referenciales del Instituto Nacional de Cáncer (INCA), BONASSA y SANTANA y de Resolución de la Directoria Colegiada (RDC) 220. La teoria sobre el tema permite obtener subsidios para acciones y prácticas seguras; apuntar condiciones ideales/legales de trabajo e instrumentalizar trabajadores de los STA para un ejercicio laboral consciente y libre de riesgos.

Descriptores: Enfermería; Servicio hospitalario de oncología, Riesgo ocupacional, Quimioterapia, Trabajador, Salud.

\section{INTRODUÇÃO}

O atual cenário epidemiológico aponta indicadores de aumento dos casos de câncer no Brasil e no mundo. Observa-se uma crescente demanda de pacientes aos serviços de saúde, à procura de atenção e tratamentos especializados. Novas drogas com poder de cura são usadas no tratamento do câncer, em contrapartida, apresentam toxicidade e efeitos adversos, o que aumenta a exposição dos trabalhadores dos Serviços de Terapia Antineoplásicas (STA) aos riscos ocupacionais químicos que advém do manuseio destas drogas.

Conceitualmente, risco ocupacional é a probabilidade de ocorrer um evento bem definido no espaço ou no tempo, que cause danos à saúde, às unidades operacionais ou dano econômico/financeiro. ${ }^{1} \mathrm{O}$ risco ocupacional químico existe mediante a ocorrência de um evento definido de contaminação. Quando um medicamento de risco é preparado, cada uma das etapas deste processo deve ser realizada sob condições e uso de práticas seguras. ${ }^{1}$

0 número de novos casos de câncer pode se elevar $50 \%$ até 2028 , principalmente nos países em desenvolvimento. São registrados, anualmente, 11 milhões de novos casos no mundo e, a cada ano, oito milhões de pessoas morrem de câncer. ${ }^{2}$ No Brasil, o câncer é a segunda causa de morte por doença. ${ }^{1}$ Segundo o Instituto Nacional do Câncer (INCA), estima-se para os anos de 2010 e 2011 , que o país terá 489.270 novos casos. $^{3}$

Considerado um dos problemas de saúde pública, para o mundo desenvolvido e em desenvolvimento, o câncer constitui-se em um desafio para a ciência, tanto na busca de tratamentos eficazes como na prevenção da doença. ${ }^{1,4}$ Dentre os tratamentos mais eficazes para o câncer, que visam uma boa qualidade de vida, estão a Cirurgia e a Radioterapia (modalidades mais antigas e de atuação localizada) e a Terapia Antineoplásica (TA), que inclui os tratamentos com agentes biológicos, o tratamento hormonal e a Quimioterapia Antineoplásica (QA) (modalidade de tratamento sistêmico). ${ }^{4}$.

A QA consiste no emprego de drogas citotóxicas, isoladas ou em combinação, que atuam sobre as células tumorais, agindo também sobre o ciclo celular das células normais 


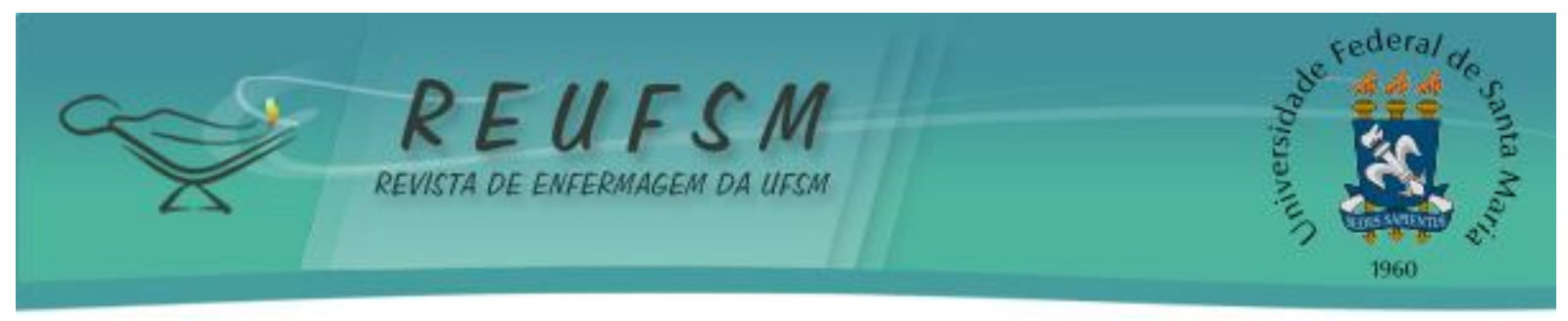

de rápida proliferação, produzindo efeitos colaterais indesejáveis e tóxicos, tanto para os indivíduos que necessitam submeter-se ao tratamento, como para os que manipulam as drogas. ${ }^{1,4-5}$ Pela sua natureza citotóxica, mutagênica, carcinogênica e fetotóxica, o preparo deve seguir normas rígidas de segurança pessoal. ${ }^{4}$ Portanto, a toxicidade das drogas se constitui em fator de risco ocupacional químico para os que as manipulam e fator determinante de adoecimento dos trabalhadores dos STA.

A importância do tema está sinalizada na Política Nacional de Segurança e Saúde do Trabalhador (PNSST) ${ }^{6}$ que traz na alínea 23 que o impacto das novas tecnologias está causando uma mudança de perfil de saúde, de adoecimento e de sofrimento dos trabalhadores. Sabe-se que a QA está incluída neste contexto tecnológico e que manipular quimioterápicos envolve riscos ocupacionais, especialmente quando as recomendações de segurança não são seguidas corretamente e as condições de trabalho são inadequadas.

A Agência Nacional de Vigilância Sanitária (ANVISA), órgão regulador e fiscalizador dos serviços de saúde, criou a Resolução da Diretoria Colegiada (RDC) $220^{7}$ que aprova o Regulamento Técnico de funcionamento dos STA com o objetivo de fixar os requisitos mínimos exigidos de funcionamento. Para tanto, levou em consideração as diretrizes da Lei Federal $\mathrm{n}^{\circ} 8080^{8}$ que trata das condições para a promoção, proteção e recuperação da saúde, como direito fundamental do ser humano, da organização e do funcionamento dos serviços.

Apesar das recomendações da legislação, alguns serviços não adotam as medidas necessárias, no sentido de adequar-se as práticas seguras no manuseio com QA. ${ }^{1,4}$ Portanto, esta questão sinaliza a não garantia da segurança dos trabalhadores dos STA, devido exposição ao risco ocupacional químico que são expostos, pelo manuseio das drogas.

Neste contexto, este estudo de atualização questiona: quais práticas de segurança, recomendadas pela legislação e literatura em relação à exposição ao risco químico, devem ser garantidas pelos STA e internalizadas pelos trabalhadores? Propõe-se, então, fazer um levantamento das ações necessárias para uma prática segura nos STA, na perspectiva de proteção da saúde do trabalhador em relação ao risco ocupacional químico. Espera-se contribuir para a revisão dos processos de trabalho dos STA das instituições hospitalares e para a melhoria da qualidade da saúde e segurança dos trabalhadores.

\section{MÉTODO}

Em 2006, por exigência do exercício fiscalizatório da ANVISA, o STA de um Hospital Público de Alta Complexidade do interior do estado do Rio grande do Sul, precisou fazer adaptações em sua estrutura física e funcional. Dentre elas, a constituição formal da Equipe Multiprofissional de Terapia Antineoplásica (EMTA), com atribuições gerais e ações prioritárias a serem desenvolvidas no STA desta instituição. Assim, foi necessário uma atualização e aprofundamento do referencial teórico em relação a vários temas, entre eles, saúde e segurança do trabalhador em relação ao risco ocupacional químico da QA, o que motivou a realização deste estudo. A partir disso, o presente artigo de atualização foi realizado, tendo por base os referenciais do INCA ${ }^{1}$, de BONASSA e SANTANA ${ }^{4}$ e da RDC $220 .^{7}$

As práticas de segurança foram categorizadas em: Segurança relativa aos profissionais dos STA; Segurança na manipulação da QA na Cabine de Fluxo Laminar; Segurança individual e coletiva; Segurança no uso de materiais; Segurança no transporte da QA após o preparo; Segurança na administração da QA; Segurança relativa ao descarte de resíduos tóxicos; Segurança nas ações após o derramamento ambiental e contaminação pessoal e Segurança no manuseio de pacientes que receberam QA. 


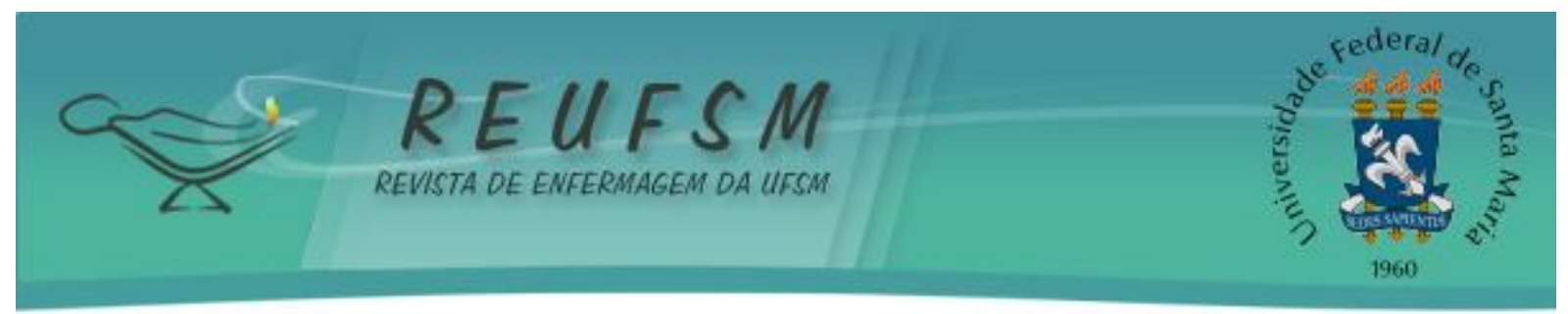

Segurança relativa aos profissionais dos STA

Os trabalhadores dos STA são definidos conforme as competências técnicas cientificas e legais, exigidas em todas as etapas do processo de uso da QA. A prescrição de antineoplásicos cabe ao médico oncologista clínico e o preparo dessas drogas é atribuição privativa do farmacêutico, ao qual compete o exercício da atividade de manipulação de drogas antineoplásicas e similares nos estabelecimentos de saúde. ${ }^{9}$ Ao enfermeiro compete "ministrar quimioterápico antineoplásico, conforme farmacocinética da droga e protocolo terapêutico"10, no entanto, "é facultativo ao Enfermeiro o preparo de drogas quimioterápicas antinéoplásicas" ". Os demais trabalhadores dos STA fazem o transporte, manuseiam excretas e materiais contaminados pela QA, fazem a limpeza e desinfecção dos ambientes e o descartes de resíduos. Todos os trabalhadores estão expostos às condições adversas no ambiente de trabalho, devido ao risco químico da QA.

As atribuições e responsabilidades individuais devem estar descritas e disponíveis, sob a forma de Procedimentos Operacionais Padrão (POPs), nos quais são descritos os passos que garantem a qualidade dos procedimentos e a segurança dos envolvidos no processo. A atualização periódica anual dos POPS e a capacitação dos trabalhadores sobre os riscos, medidas de proteção e condutas em acidentes devem estar garantidos.

0 ambiente hospitalar favorece o adoecer das pessoas que nele trabalham, porque, aparentemente, não há preocupação das instituições de saúde com a proteção, promoção e manutenção da saúde de seus empregados. ${ }^{12}$ Por exigência legal, os STA devem elaborar e implementar o Programa de Controle Médico de Saúde Ocupacional $(\mathrm{PCMSO})^{7}$, que tem sua obrigatoriedade estabelecida pela NR $-7^{13}$ a todos os serviços e instituições na admissão dos empregados, tendo como objetivo a promoção e preservação da saúde dos trabalhadores. Também é exigência implementar o Programa de Prevenção de Riscos Ambientais (PPRA) ${ }^{14}$, a fim de proporcionar uma melhor avaliação e gerenciamento dos fatores de riscos ocupacionais, como forma de proteção aos trabalhadores.

Outras ações indispensáveis em relação ao gerenciamento da segurança dos profissionais são: manter fichas de registro para acompanhamento de acidentes profissionais, com registros completos e precisos, para fins legais, registros epidemiológicos, controle clínico e pesquisa; estabelecer avaliações clínica e laboratorial inicial, semestral ou anual dos trabalhadores, para detectar precocemente alterações que possam estar relacionadas ao manuseio de quimioterápicos e avaliar as medidas de proteção empregadas, de acordo com o PCMSO; supervisionar o cumprimento das normas de segurança; redimensionar mulheres grávidas e nutrizes das atividades que envolvam QA; limitar o número de profissionais que a manipulam e fazer rodízio entre as pessoas envolvidas no preparo e administração. A maioria dos trabalhadores considera que a manipulação de QA oferece riscos à sua saúde, não sendo capazes, porém, de identificar claramente estes riscos. ${ }^{15}$

\section{Segurança na manipulação da QA na Cabine de Fluxo Laminar}

A manipulação da QA parenteral é o momento de maior risco ocupacional, pois serão efetuadas ações diretas com o medicamento. Deve ser realizada sob condições adequadas para minimizar este risco. Muitas vezes, os materiais e mobiliários disponibilizados não são coerentes às necessidades dos trabalhadores e podem interferir de forma negativa para as garantias dos meios de proteção. ${ }^{16}$

O preparo da QA deve ser feito em Cabine de Fluxo Laminar classe II B2, com acesso restrito e por profissionais treinados e adequadamente paramentados. A cabine 


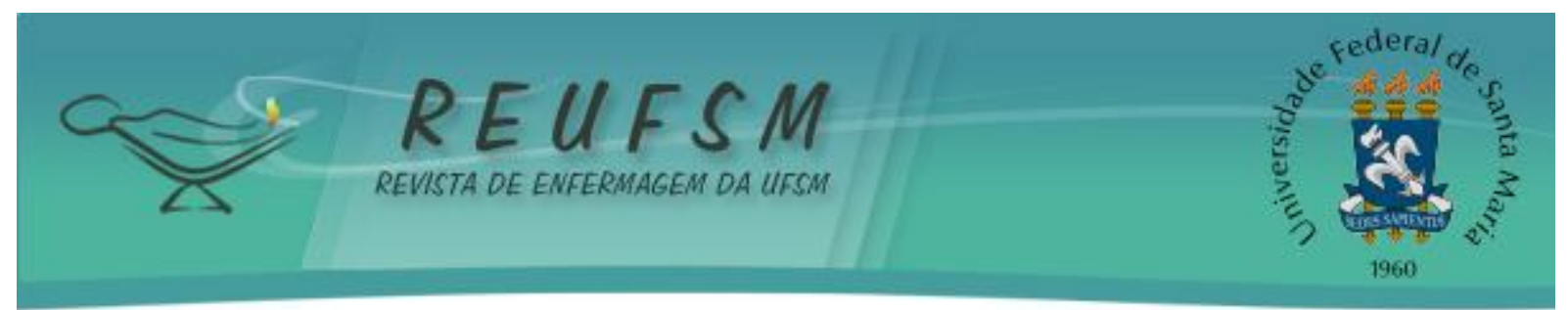

deve ser ligada, no mínimo, 30 minutos antes do início da manipulação e permanecer ligada por 30 minutos após a conclusão do preparo. Qualquer interrupção do funcionamento implica em imediata paralisação das atividades. A exaustão externa da cabine garante a proteção pessoal e ambiental. Todas as superfícies de trabalho, inclusive a cabine, devem ser limpas e desinfetadas antes e depois de cada sessão de preparação, com produtos regularizados junto a ANVISA/MS.

A superfície de preparo da cabine deve ser coberta com um protetor, impermeável na sua face inferior e absorvente em sua face superior, trocado ao final do plantão ou após cada contaminação. A manipulação deve associar a técnica asséptica à de biossegurança, todos os materiais envolvidos no preparo dos medicamentos devem ser submetidos aos procedimentos de limpeza (lavagem) e desinfecção (alcoolização).

A manipulação da ampola e do frasco-ampola deve ser cuidadosa, respeitando o equilíbrio das pressões de dentro e de fora, a fim de evitar a liberação de aerossóis ou de gotículas de droga, sobre a superfície de preparo. Os frascos, resíduos da ampola, gaze, equipos, agulhas e luvas usadas, devem ser descartados, dentro da própria capela, em recipiente apropriado, impermeável e resistente. Os mesmos cuidados valem para medicamentos sob a forma de pó liofilizado.

0 fracionamento e diluição de medicamentos de uso oral também devem ser realizados em capela. É proibido comer, beber, fumar e aplicar cosméticos na área de preparo. A geladeira que armazena citostático deve ser de uso exclusivo.

\section{Segurança individual e coletiva}

Outro fator importante em relação à biossegurança é o uso de EPIs. Este uso é regulamentado pela NR $-6^{17}$, a qual considera EPI todo o dispositivo ou produto de uso individual utilizado pelo trabalhador, destinado à proteção de riscos suscetíveis de ameaçar a segurança e a saúde no trabalho. As recomendações estabelecidas são:

$\mathrm{Na}$ área de preparo da QA, todos os trabalhadores devem usar dois pares de luvas estéreis, de punho longo e sem talco, trocado o par de cima a cada hora e a cada duas horas os dois pares. As mãos devem ser lavadas rigorosamente antes e após o uso da luvas. 0 avental longo ou macacão deve ser de uso restrito, preferencialmente descartável, com baixa liberação de partículas, baixa permeabilidade, frente fechada, com manga longa e punho elástico. Se for reutilizável, deve ser guardado separadamente, com lavagem exclusiva e troca a cada manipulação. Uso de protetor respiratório tipo máscara facial, com filtro de carvão ativado, o qual age como filtro químico para partículas de até 0,2 micra $(\mu)$ e óculos de proteção com laterais fechadas.

$\mathrm{Na}$ área de administração da QA, todos os envolvidos no processo devem usar luvas e aventais descartáveis de baixa permeabilidade, sendo facultada a utilização de óculos e proteção respiratória.

Nas duas áreas, preparo e administração, deve conter lava olhos (equipamento projetado para irrigação dos olhos) e chuveiro, para o caso de exposição severa as substâncias de risco. O lava olhos, o chuveiro e a cabine constituem os equipamentos de proteção coletiva.

É vetado iniciar qualquer atividade relacionada ao manuseio de QA na falta de EPIs. Estes devem ser avaliados diariamente, quanto ao estado de conservação e segurança, estando disponíveis e armazenados em locais de fácil acesso.

Por vezes, o não uso de medidas protetoras é tida como uma forma de tornar o contato com os usuários mais agradável, por estes já se encontrarem sensibilizados com a doença ${ }^{16}$. Porém, é obrigatório o uso de EPI especificamente para o manuseio de quimioterápicos antineoplásicos. 


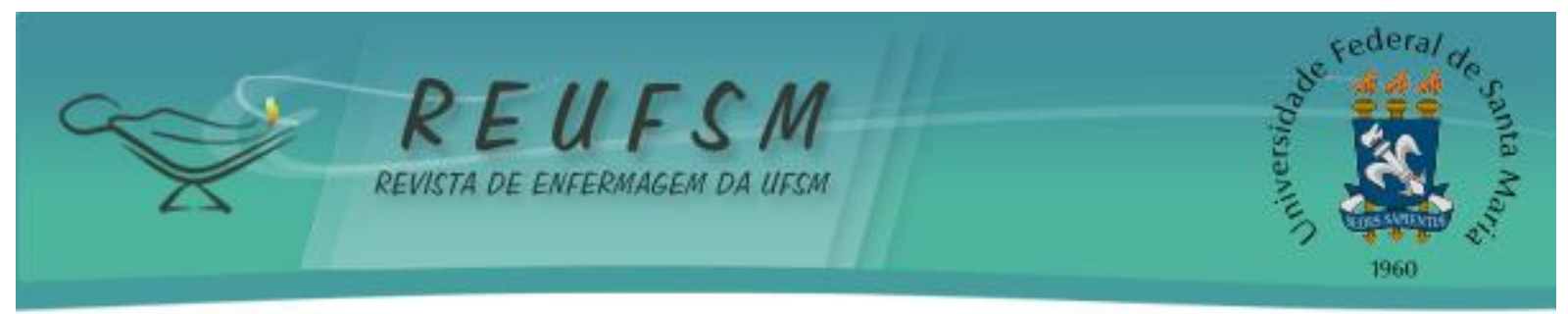

\section{Segurança no uso de materiais}

0 uso de alguns dispositivos especiais é de grande importância para manter a segurança no manuseio da QA. Estes são: seringa com conexão rosqueável (luer lock); uso de vedador rosqueável para seringas; dispositivo desaerolizante para manipulação de frasco-ampola, que impede a liberação de aerossóis; sistema fechado, com equipo com infusor lateral conectado a bolsa de solução e previamente preenchido pelo líquido de infusão e agulha ponta romba, sem bisel.

É imprescindível que haja uma articulação entre os funcionários e a gerência para avaliar e, se for o caso, substituir os materiais defeituosos e inadequados, assim como contatar as empresas para realização de treinamentos, para adaptação dos funcionários, com os novos materiais. ${ }^{16}$

\section{Segurança no transporte da QA após o preparo}

Após identificação, rotulagem e embalagem, a QA preparada segue da Central de Preparo da farmácia para os setores de administração de curta duração (Ambulatórios) ou de longa duração (Unidades de Internação). A QA deve ser conservada e transportada de maneira que garanta condições de estabilidade físico-química.

0 transporte interno da QA deve ser feito em um carro de transporte, dentro de recipientes isotérmicos exclusivos com termômetro, tampa e alça de segurança, protegidos de intempéries e da incidência direta da luz solar. Os trabalhadores devem possuir treinamento específico de biossegurança, para atuarem em situações de acidentes e emergências.

Deve fazer parte do carro de transporte o "Kit" de derramamento. Este necessita conter no mínimo, luvas de procedimento, avental de baixa permeabilidade, compressas absorventes, proteção respiratória, proteção ocular, descrição do procedimento (POP de derramamento), formulário para o registro de acidentes e recipiente identificado para recolhimento dos resíduos. No caso de contaminação acidental no transporte, fazer a notificação compulsória do ocorrido ao responsável pela preparação, bem como, tomar as providências de descontaminação e limpeza, conforme POPs.

\section{Segurança na administração da QA}

Os riscos de exposição durante a administração de QA ocorrem mais comumente durante a injeção da droga "em push" e na conexão e desconexão de equipos, seringas e tampas. Embora os trabalhadores reconheçam que há riscos na atividade de administração de QA, alguns deles crêem que esse risco não está presente quando há utilização de sistema fechado. ${ }^{16}$

Porém, sabe-se que ocorre exposição por uso de materiais inadequados e por existência de vazamentos. Portanto, o uso de EPIs, materiais apropriados e cuidados especiais devem ser rigorosamente seguidos.

Entre os principais cuidados na administração da QA estão a higienização rigorosa das mãos, a manutenção de uma gaze próxima às conexões, especialmente no momento da introdução ou retirada de equipos e conectores e a não retirada de ar das seringas, pois estas devem vir prontas, da central de preparo, para a aplicação. No caso de administração de citostático via oral, havendo possibilidade de respingo, usar os mesmos cuidados. 


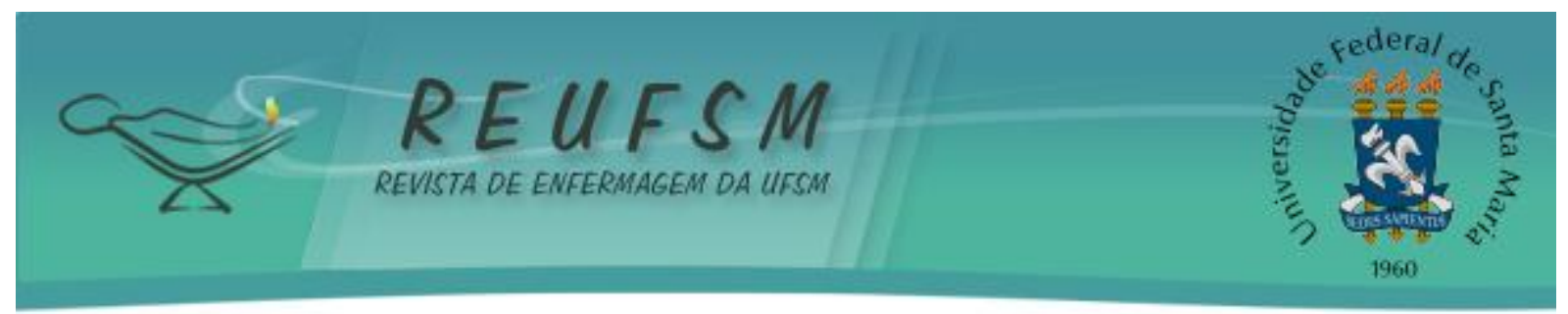

\section{Segurança relativa ao descarte de resíduos tóxicos}

Com a finalidade de minimizar os riscos ocupacionais e os riscos de danos ao meio ambiente, todos os serviços devem implantar o Programa de Gerenciamento dos Resíduos de Resíduos de Serviço de Saúde (PGRSS). ${ }^{18}$ Os perfurocortantes devem ser descartados separadamente, imediatamente após o uso, em recipientes rígidos, resistentes à punctura, ruptura ou vazamento, com tampa, identificado com a simbologia padronizada que identifica o resíduo tóxico.

As agulhas descartáveis devem ser desprezadas junto com as seringas, sendo proibido reencapá-las ou retirá-las manualmente. Os frascos vazios de QA ou com restos de medicação, os frascos de soros vazios e equipos, gases, algodão e luvas contaminados por QA devem ser descartados em sacos plásticos nove $\mu$, depositados em recipiente para lixo identificado como material tóxico. Quando os recipientes estiverem cheios até $2 / 3$ de sua capacidade, devem ser descartados adequadamente.

Em estudo realizado sobre acidentes de trabalho em hospitais, evidenciou-se que a maioria ocorreu durante o descarte de material, e a maioria dos funcionários não utilizava EPIs. ${ }^{19} \mathrm{O}$ descarte e o transporte de resíduos tóxicos devem ser feito por pessoal treinado e paramentado.

\section{Segurança nas ações após o derramamento ambiental e contaminação pessoal}

Deve-se manter "Kit" derramamento identificado e disponível, em todas as áreas onde são realizadas atividades com QA. No caso de acidente por derramamento, com contaminação pessoal, deve-se remover imediatamente o vestuário ou luvas, devido à contaminação, descartando em saco plástico apropriado para manuseio seguro. No caso de aventais não descartáveis, devem ser acondicionados em saco plástico de nove $\mu$ e levados à lavanderia para pré-lavagem em separado. As mãos e as áreas da pele atingida devem ser lavadas rigorosamente com água e sabão. No caso dos olhos ou outras mucosas lavar com água ou solução isotônica, por pelo menos cinco minutos. Todos os acidentes relacionados à QA devem ser registrados em formulário específico. Providenciar avaliação médica e encaminhar o acidentado para acompanhamento do Serviço de Segurança e Saúde do Trabalhador da instituição.

No caso de acidente ambiental é necessário paramentar-se, antes de iniciar o processo de descontaminação, com avental, duas luvas em cada mão e proteção facial. Se a contaminação ocorrer na cabine e houver contaminação do filtro, esta deve ser isolada até a troca do mesmo. Na contaminação do ambiente, delimitar a área de derramamento com compressas, identificar e restringir acesso, recolher os pós com compressa absorvente umedecida e os líquidos com compressa absorvente seca. Recolher e descartar os fragmentos, lavando a área com água e sabão em abundância. Em acidentes com derramamento de mais de cinco mililitros, deve ser usado máscara com filtro de carvão ativado.

A subnotificação deve ser evitada, pois as causas desta foram evidenciadas como a desinformação em relação aos riscos e aos aspectos epidemiológicos e jurídicos que envolvem os acidentes, a submissão dos trabalhadores às condições impostas pelos serviços, a falta de tempo para notificação e o medo de perder o emprego se o fizerem. ${ }^{20}$ Portanto, todo o acidente deve ser registrado no prontuário médico das pessoas envolvidas.

\section{Segurança no manuseio de pacientes que receberam QA}

No manuseio de excretas e de roupas contaminadas com fluídos corporais e excretas de pacientes que receberam QA nas últimas 48 horas, deve-se usar luvas de 


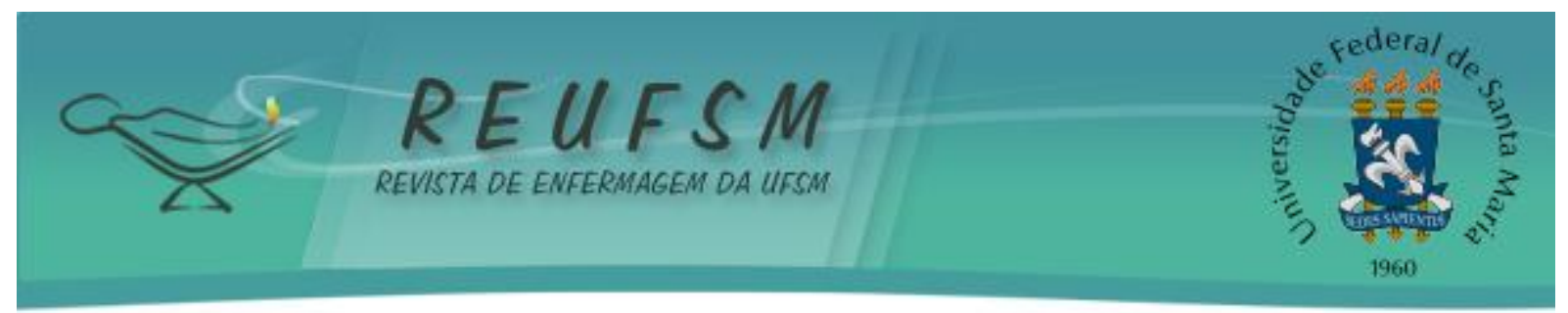

procedimento, máscaras e aventais de manga longa. As roupas contaminadas devem ser encaminhadas à lavanderia acondicionadas em saco plástico nove $\mu$, amarrado e rotulado com identificação de resíduo tóxico. As secreções e excretas devem ser desprezadas com cautela, para evitar a contaminação por respingos. Deve-se oferecer coletor de urina masculino com abertura pequena e tampar o vaso sanitário antes de acionar descarga, fazê-la duas vezes.

As informações descritas nas categorias de segurança, correspondem aos cuidados que devem ser observados em todas as etapas do processo de uso da QA. Portanto, é imprescindível que todos os profissionais envolvidos sejam adequadamente informados, treinados e supervisionados para seu cumprimento.

\section{CONSIDERAÇÕES FINAIS}

Atender aos requisitos mínimos exigidos para o funcionamento dos STA, no que diz respeito aos aspectos de segurança, deve ser uma das prioridades dos gestores das instituições públicas ou privadas de saúde e dos profissionais envolvidos neste processo. Por outro lado, cabe ao órgão de vigilância sanitária, no exercício de fiscalização, inspecionar as inadequações à legislação ou a constatação de possíveis irregularidades, com emissão do relatório técnico de inspeção. 0 exercício de vigilância e fiscalização feito por órgão competente, no caso a ANVISA, avalia a qualidade dos serviços oferecidos, bem como certifica se a segurança e a saúde dos trabalhadores estão garantidas. Portanto, o ato da fiscalização, contribui para o aperfeiçoamento e adequações dos serviços à legislação.

A conscientização e os esforços dos trabalhadores colaboram para o exercício pleno da cidadania. Para tanto, é preciso manter os conhecimentos atualizados em relação às políticas públicas de saúde e a legislação que os ampara, a qual os serviços devem estar adaptados. A construção da consciência profissional, do conhecimento científico, técnico e humanístico e o desenvolvimento do pensamento crítico - reflexivo são fundamentais para a formação do perfil do cidadão trabalhador dos tempos modernos. Este estudo buscou sustentação teórica, fundamentada em leis e resoluções, para subsidiar as práticas e ações dos trabalhadores dos STA, no sentido de contribuir para evitar ou minimizar a ocorrência de acidentes e doenças ocupacionais, bem como, apontar as condições adequadas de trabalho para a qualificação dos serviços e instrumentalização dos trabalhadores, com vistas ao exercício laboral seguro e livre de riscos químicos.

\section{REFERÊNCIAS}

1. Instituto Nacional de Câncer (Brasil). Ações de enfermagem para o controle do câncer: uma proposta de integração ensino-serviço. 3. ed. atual. ampl. Rio de Janeiro: INCA, 2008.

2. Grayley MW. OMS pede prioridade para câncer. Disponível em: <http://www.unmultimedia.org/radio/portuguese/detail/151346.html>. Acesso em: $15 \mathrm{de}$ julho de 2010.

3. Instituto Nacional de Câncer Brasil terá quase meio milhão de novos casos de câncer em 2010. Disponível em: <http://www.inca.gov.br/releases/press_release_view.asp?ID=2282>. Acesso em 15 de jul. 2010.

4. Bonassa EMA, Santana TR. Enfermagem em terapêutica oncológica. 3. ed. São Paulo, SP: Atheneu, 2005.

5. Mozachi N, Souza VHS. O Hospital: manual do ambiente hospitalar. 2. ed. Curitiba, PR: 


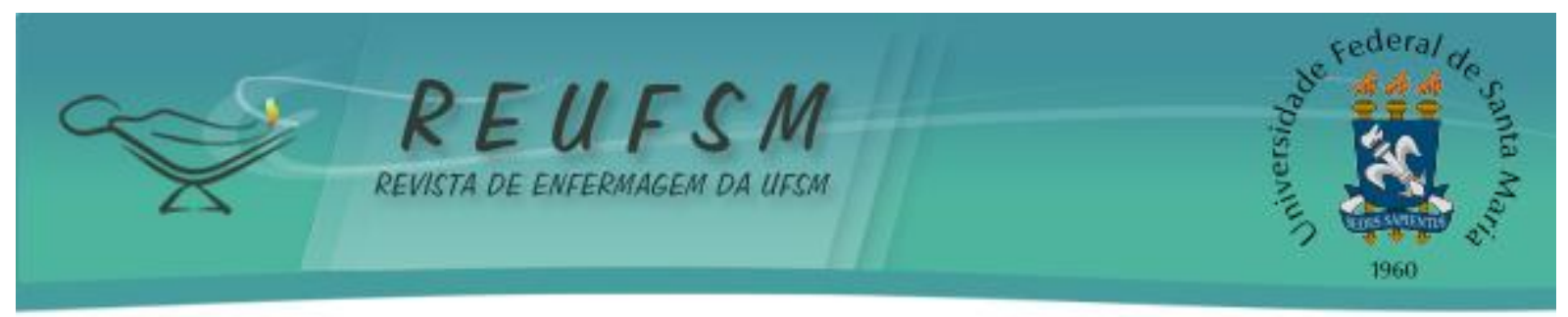

Manual Real Ltda., 2005.

6. Brasil. Política nacional de segurança e saúde do trabalhador. Brasília, DF: Ministério da Saúde, 2004a.

7. Brasil. Resolução $n^{\circ}$. 220, de 21 de setembro de 2004. Dispõe sobre as normas técnicas para o funcionamento dos Serviços de Terapia Antineoplásica. Brasília, DF: ANVISA, 2004b.

8. Brasil. Lei $n^{\circ}$. 8080, de 19 de setembro de 1990. Dispõe sobre as condições para a promoção, proteção e recuperação da saúde, a organização e o funcionamento dos serviços correspondentes e dá outras providências. Diário Oficial da União. Brasília, DF, 1990.

9. Brasil. Resolução $\mathrm{N}^{\circ}$ 288/96. Dispõe sobre a competência legal para o exercício da manipulação de drogas antineoplásicas pelo farmacêutico. Conselho Federal de Farmácia. Brasília, DF, 1996.

10. Brasil. Resolução COFEN-210, de 01 de julho de 1998. Dispõe sobre a atuação dos profissionais de Enfermagem que trabalham com quimioterápicos antineoplásicos. Conselho Federal de Enfermagem, Rio de Janeiro, 1998. Disponível em: <http://www.portalcofenrs.gov.br>. Acesso em 14.jul.2010.

11. Brasil. Resolução COFEN $n^{\circ}$. 257, de 12 de julho de 2001. Acrescenta dispositivo ao Regulamento aprovado pela Resolução COFEN N ${ }^{\circ}$. 210/98, facultando ao Enfermeiro o preparo de drogas quimioterápicas antineoplásicas. Conselho Federal de Enfermagem, Rio de Janeiro, 2001. Disponível em: <http://www.portalcofen-rs.gov.br>. Acesso em 15.jul.2010.

12. Xelegati R e Robazzi MLCC. Riscos químicos a que estão submetidos os trabalhadores de enfermagem: uma revisão de literatura. Rev. Latino-Am. Enfermagem. 2003; 1(3): 350356.

13. Associação Brasileira de Normas Técnicas. NR - 07: Programa de Controle Médico de Saúde Ocupacional - PCMSO. (107.000-2). MTE, 1978. Disponível em: <http://www.mte.gov.br/legislação/normas_regulamentadoras/nr_07_at.pdt>. Acesso em 14 jul.2010.

14. Associação Brasileira de Normas Técnicas. NR - 09: programa de prevenção de riscos ambientais - PPRA. (109.000-3). MTE, 1978. Disponível em: <http://www.guiatrabalhista.com.br/legislacao/nr/nr9.htm>. Acesso em: 14. jul. 2010.

15. Rocha FLR, Marziale MHP, Robazzi MLCC. Perigos potenciais a que estão expostos os trabalhadores de enfermagem na manipulação de quimioterápicos antineoplásicos: conhecê-los para preveni-los. Rev. Latino-Am. Enfermagem. 2004; 12(3): 511-517.

16. Maia PG. A atividade da equipe de enfermagem e os riscos relacionados à exposição à quimioterápicos antineoplásicos no setor de oncologia de um hospital público do estado do Rio de Janeiro [tese]. Rio de Janeiro: Escola Nacional de Saúde Pública Sergio Arouca, 2009. 144 p.

17. Associação Brasileira de Normas Técnicas. NR - 06: Equipamento de Proteção Individual - EPI. (206.000-0/I0). MTE, 1998. Disponível em: <http://www.staweb.com.br/index. php?option...> Acesso em: 14.jul.2010.

18. Brasil. Resolução № 306 de 07 de dezembro de 2004. Dispõe sobre o regulamento técnico para o gerenciamento de resíduos dos serviços de saúde. Diário Oficial da União. Brasília, DF: ANVISA, 2004. 


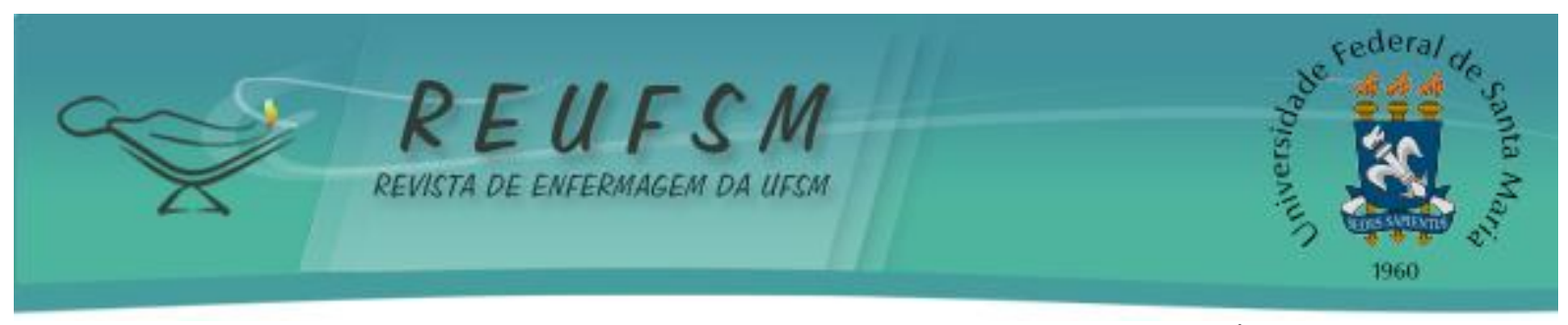

19. Oliveira BC, Kluthcovsky ACGC, Kluthcovsky FA. Estudo sobre ocorrências de acidentes de trabalho com material biológico em profissionais de enfermagem de um hospital. Cogitare Enferm. 2008; 13(2): 194-205.

20. Cavalcanti, CAV, Enders, BC, Menezes, RMP, Medeiros, SM. Riscos ocupacionais do trabalho em enfermagem: uma análise contextual. Ciência, Cuidado e Saúde. 2006; v.5,n.1,p.88-97.

Data de recebimento:23/11/2010

Data de aceite:14/11/2011

Contato com autora responsável: Maria Elaine de Oliveira Bolzan

E-mail: mariaelaine.bolzan@bol.com.br. 